\title{
In situ study of heavy ion irradiation response of immiscible $\mathrm{Cu} / \mathrm{Fe}$ multilayers
}

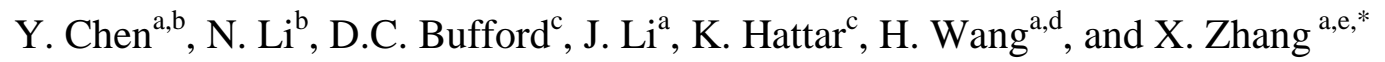 \\ ${ }^{a}$ Department of Materials Science and Engineering, Texas A\&M University, College Station, \\ TX 77843 \\ ${ }^{\mathrm{b}}$ MPA-CINT, Los Alamos National Laboratory, Los Alamos, NM 87545, USA \\ ${ }^{\mathrm{c}}$ Sandia National Laboratories, Albuquerque, NM 87185, USA \\ ${ }^{\mathrm{d}}$ Department of Electrical and Computer Engineering, Texas A\&M University, College Station, \\ TX 77843 \\ ${ }^{\mathrm{e}}$ Department of Mechanical Engineering, Texas A\&M University, College Station, TX 77843 \\ * Corresponding author: X. Zhang, zhangx@tamu.edu, Tel: (979) 845-2143
}

\begin{abstract}
Recent studies show that immiscible metallic multilayers with incoherent interfaces can effectively reduce defect density in ion irradiated metals by providing active defect sinks that capture and annihilate radiation induced defect clusters. Although it is anticipated that defect density within the layers should vary as a function of distance to the layer interface, there is, to date, little in situ TEM evidence to validate this hypothesis. In this study monolithic $\mathrm{Cu}$ films and $\mathrm{Cu} / \mathrm{Fe}$ multilayers with individual layer thickness, h, of 100 and $5 \mathrm{~nm}$ were subjected to in situ $\mathrm{Cu}$ ion irradiation at room temperature to nominally 1 displacement-per-atom inside a transmission electron microscope. Rapid formation and propagation of defect clusters were observed in monolithic $\mathrm{Cu}$, whereas fewer defects with smaller dimensions were generated in $\mathrm{Cu} / \mathrm{Fe}$ multilayers with smaller h. Furthermore in situ video shows that the cumulative defect
\end{abstract}


density in $\mathrm{Cu} / \mathrm{Fe} 100 \mathrm{~nm}$ multilayers indeed varies, as a function of distance to the layer interfaces, supporting a long postulated hypothesis.

Keywords: in situ ion irradiation; heavy ion irradiation; immiscible interfaces; $\mathrm{Cu} / \mathrm{Fe}$ multilayers; size effect

\section{Introduction}

High energy neutrons and heavy ions can induce significant densities of interstitials, vacancies, and defect clusters in irradiated metallic materials, and correspondingly lead to degradation of their performance in nuclear reactors. For instance neutron irradiation to a dose of several to tens of displacements-per-atom (dpa) may lead to void swelling, radiation embrittlement, and radiation creep in a variety of metallic materials with face-centered cubic (FCC) structures (1-4). Meanwhile advanced nuclear energy systems call for extraordinary materials that can sustain neutron irradiation damage up to 200 dpa (5-9). Such a daunting challenge drives extensive materials research towards the design and discovery of advanced radiation-tolerant materials.

In general, there are several approaches to enhance radiation tolerance in materials (5). First, the inherent radiation tolerance of metallic materials depends on intrinsic properties, specifically bonding and crystal structure. Stronger atomic bonding in metals corresponds to higher threshold displacement energy, resulting in less radiation damage (10). Crystal structure is another key factor in terms of radiation damage. For instance the visible density of defect clusters is greater in FCC $\mathrm{Cu}$ than in body-centered cubic (BCC) Fe subjected to the same dose of radiation $(11,12)$. Molecular dynamics (MD) simulations suggest that although the total 
defect densities in $\mathrm{Cu}$ and $\mathrm{Fe}$ are very similar at the same dose, cluster size in $\mathrm{Cu}$ at the same dose is significantly larger than that in Fe, due to the formation of large vacancy clusters in the cascade core in $\mathrm{FCC} \mathrm{Cu}$, and the greater number of free vacancies in BCC Fe (13). Bacon et al also suggested that defect clusters in irradiated BCC Fe are relatively small and more finely dispersed, which enhances recombination during radiation (14). Similarly, ferritic/martensitic steels with primarily BCC structures are frequently shown to possess better void swelling resistance than austenitic stainless steels with FCC crystal structures (2). Second, an intensively investigated approach is to design materials with high-density defect sinks, including grain boundaries (GBs) (15-19), twin boundaries (20-23), and phase boundaries (24-31). A majority of these boundaries, acting as unbiased defect sinks, can absorb point defects and their clusters, and promote their recombination $(32,33)$. For instance nanocrystalline (nc) metals with a high volume ratio of GBs showed significantly reduced defect density during radiation (16, 34-36), and recently direct evidence on defect cluster absorption by high angle GBs in nc Ni was reported via in situ radiation experiments inside a transmission electron microscope (TEM) (37). In nanotwinned $\mathrm{Ag}$ with a high density of twin boundaries, the density of irradiation induced defects decreased at smaller average twin spacing $(20,21)$, due to a twin boundary affected zone of radiation induced defect density (23). Furthermore Zhang's group demonstrated that by deliberately introducing voids into nanotwinned $\mathrm{Cu}$, incoherent twin boundaries (ITBs) can act as diffusion channels to deliver radiation induced defects into voids, significantly mitigating radiation damage (22).

Meanwhile there are increasing studies on the role of layer interfaces in radiation damage in multilayers $(24-26,38,39)$ and various types of metallic multilayer systems have been investigated, including those with $\mathrm{FCC} / \mathrm{BCC}$ interfaces $(\mathrm{Cu} / \mathrm{Nb}(25,26,29,40,41), \mathrm{Cu} / \mathrm{V}(42-$ 
44), $\mathrm{Cu} / \mathrm{Mo}$ (45), $\mathrm{Cu} / \mathrm{W}(46), \mathrm{Al} / \mathrm{Nb}$ (47), $\mathrm{Ag} / \mathrm{V}(48,49)), \mathrm{FCC} / \mathrm{FCC}$ interfaces (e.g. $\mathrm{Cu} / \mathrm{Ni}(50)$, $\mathrm{Cu} / \mathrm{Co}(51) \mathrm{Ag} / \mathrm{Ni}(52,53)), \mathrm{BCC} / \mathrm{BCC}$ interfaces (Fe/W (54)), and BCC/amorphous interfaces $\left(\mathrm{Fe} / \mathrm{Fe} 2 \mathrm{Zr}(55), \mathrm{Fe} / \mathrm{a}-\mathrm{Y}_{2} \mathrm{O}_{3}(31), \mathrm{Fe} / \mathrm{TiO}_{2}(30)\right)$. In addition, it is worth mentioning that coherent interfaces can also mitigate radiation damage $(51,56)$. The study of $\mathrm{He}$ ion irradiated $\mathrm{Cu} / \mathrm{Fe}$ nanolayers shows that swelling is mitigated in $\mathrm{FCC} / \mathrm{FCC} \mathrm{Cu} / \mathrm{Fe}$ with layer thickness of $1 \mathrm{~nm}$, resulting from the suppression of bubble size by coherent layer interfaces (56). Among them, layer interfaces in immiscible systems are more effective (than those in miscible counterparts) for mitigating radiation damage as they inherently recover from radiation induced intermixing $(24,38)$. High-density misfit dislocations at incoherent interfaces would serve as defect sinks for radiation-induced point defects and catalysts for efficient Frenkel pair recombination (41, 57). As many layer interfaces are effective defect sinks, one anticipates that, similar to the existence of GB denuded zones near high angle GBs, interface affected zones should exist near layer interfaces in immiscible multilayers. Han et al. reported void-denuded zones in $\mathrm{Cu} / \mathrm{Nb}$ nanolayered structure by ex situ radiation experiments (58). However, there is little in situ evidence to validate if the defect density is indeed lower close to the layer interfaces.

In situ irradiation experiments inside a TEM provide a unique opportunity to investigate defect generation, migration kinetics, and interactions between radiation-induced defect clusters and defect sinks. Although multilayer systems have been extensively studied by ex situ irradiation techniques $(19,24-26,38)$, there are limited in situ evidence that show the influence of layer thickness on radiation tolerance in $\mathrm{FCC} / \mathrm{BCC}$ multilayer systems. Here we use $\mathrm{Cu} / \mathrm{Fe}$ multilayers as a model system to investigate, via an in situ radiation technique, thickness dependent response to radiation damage under heavy ion irradiation. $\mathrm{Cu}$ and $\mathrm{Fe}$ were selected as both are classical model systems for FCC and BCC crystal structures, and they have drastically 
different responses to radiation damage. This study shows that there is a size dependent variation of defect density in multilayers, and the concentration of defects indeed varies as a function of distance to layer interfaces, manifesting the existence of an interface affected zone.

\section{Experimental}

$\mathrm{Cu} / \mathrm{Fe}$ multilayer films with individual layer thickness, h, of 100 and $5 \mathrm{~nm}$ (referred to as $\mathrm{Cu} / \mathrm{Fe} 100 \mathrm{~nm}$ and $\mathrm{Cu} / \mathrm{Fe} 5 \mathrm{~nm}$ hereafter) were magnetron sputtered at room temperature on HFetched $\mathrm{Si}$ (110) substrates. The chamber was evacuated to a base pressure less than $8 \times 10^{-8}$ torr prior to deposition. Before the deposition of $\mathrm{Cu} / \mathrm{Fe}$ multilayers, a $100 \mathrm{~nm}$-thick $\mathrm{Cu}$ seed layer was deposited. Details of the deposition parameters were reported previously (59). Crosssectional TEM (XTEM) samples were prepared by dimpling and low angle $\left(5^{\circ}\right)$ low energy $(3.5$ $\mathrm{keV}) \mathrm{Ar}$ ion milling and subsequent ion polishing (2 keV).

In situ ion irradiation experiments were conducted at room temperature in a JEOL JEM2100 TEM operated at $200 \mathrm{kV}$ in the Ion Beam Lab at Sandia National Laboratories (60). The defect evolution in the coarse-grained $\mathrm{Cu}$ specimen was evaluated by using (111) two-beam imaging condition. A $6 \mathrm{MV}$ EN Tandem ion accelerator was used to generate a $3 \mathrm{MeV} \mathrm{Cu}^{3+}$ beam. The ion beam entering the microscope forms an angle of $90^{\circ}$ to the vertical transmitted electron beam. The TEM thin foils were tilted by $20-30^{\circ}$ relative to the vertical axis during the in situ radiation studies. Special attention was paid to ensure the layer interfaces were edge-on during in situ radiation experiments in TEM. Depth-dependent damage and defect concentration profiles were calculated by the Stopping and Range of Ions in Matter software package (SRIM2008) using full damage cascades mode $(61,62)$. The $\mathrm{Cu} / \mathrm{Fe}$ multilayers with equal layer thickness were simplified as $\mathrm{Cu}_{50} \mathrm{Fe}_{50}$ alloys for simulation. SRIM simulations show that most $\mathrm{Cu}$ ions at $3 \mathrm{MeV}$ pass entirely through the thin specimen, leaving behind only displacement 
damage in the irradiated TEM foil. Subsequent ex situ TEM characterization was carried out on an FEI Tecnai G2 F20 Super Twin microscope operated at $200 \mathrm{kV}$. The average thickness of TEM thin foils was determined to be $\sim 100 \mathrm{~nm}$, by using a convergent beam electron diffraction (CBED) technique (63). The dimension of individual defects was measured along their short axis. The statistics on the number of defects per unit area was collected from a large number of snapshots (images) captured during in situ radiation experiments. The average defect density was

calculated by using the number of defects per unit area and the measured average TEM foil thickness. The error bar was determined from standard deviations among numerous measurements from various micrographs. To obtain defect statistics in $\mathrm{Kr}$ ion irradiated $\mathrm{Cu} / \mathrm{Fe}$ $100 \mathrm{~nm}$ and $\mathrm{Cu} / \mathrm{Fe} 5 \mathrm{~nm}$ multilayers, multiple TEM image sizes were used with dimensions of $350 \times 350 \mathrm{~nm}$ and $120 \times 120 \mathrm{~nm}$, respectively.

\section{Results}

Microstructures of monolithic $\mathrm{Cu}, \mathrm{Cu} / \mathrm{Fe} 100 \mathrm{~nm}$ and $\mathrm{Cu} / \mathrm{Fe} 5 \mathrm{~nm}$ multilayers irradiated by $\mathrm{Cu}$ ions at $3 \mathrm{MeV}$ are compared in TEM micrographs in Fig. 1. In monolithic $\mathrm{Cu}$ irradiated to a nominal dose of $0.5 \mathrm{dpa}\left(2.5 \times 10^{14}\right.$ ions $\left./ \mathrm{cm}^{2}\right)$, high-density defect clusters were generated (Figs. 1a). In comparison, irradiation to $1 \mathrm{dpa}\left(5 \times 10^{14}\right.$ ions $\left./ \mathrm{cm}^{2}\right)$ led to a moderate increase in loop density in the $\mathrm{Cu}$ layers of $\mathrm{Cu} / \mathrm{Fe} 100 \mathrm{~nm}$ samples (Figs. 1b). Columnar grains with an average grain size of $16 \mathrm{~nm}$ in Fe layers remained after irradiation. Few radiation-induced defect clusters were detected in irradiated $\mathrm{Cu} / \mathrm{Fe} 5 \mathrm{~nm}$ nanolayers (Figs. 1c).

Several TEM micrographs in Fig. 2 recorded during in situ radiation (up to 1 dpa) of $\mathrm{Cu} / \mathrm{Fe} 100 \mathrm{~nm}$ multilayers revealed microstructural evolution. As shown in Fig. 2a, the asdeposited multilayer had a low defect density. This limited number of defects might have been 
produced during growth or by the Ar ion milling. At a radiation dose of 0.1 dpa, a few defects appeared in $\mathrm{Cu}$ layers. While many of these defects have round geometry suggestive of dislocation loops, some defects with triangular geometry were also frequently identified suggestive of stacking-fault tetrahedra (SFT). The exact nature of these defects could not be determined due to the dynamic nature of the in situ TEM experiment, however both of these defect structures are often observed in irradiated $\mathrm{Cu}(64)$. With the increase of radiation dose to 0.5 and $1 \mathrm{dpa}$, the dimensions of the defect clusters increased monotonically without significant increase in defect density in the $\mathrm{Cu}$ layers. Few visible defect clusters appeared in the Fe layers throughout the entire radiation experiment. In contrast defects were readily visible and appeared much more frequently in the $\mathrm{Cu}$ layers during in situ radiation, permitting us to collect reliable statistical data for defect clusters in the irradiated $\mathrm{Cu}$ layers. In addition, no significant indication of intermixing along layer interfaces was observed in the irradiated multilayers.

The $\mathrm{Cu} / \mathrm{Fe} 5 \mathrm{~nm}$ multilayer showed the accumulation of significantly less displacement damage defects under identical radiation environments. As marked in Fig. 3, several pre-existing growth defects (marked as 1-4 in blue arrows) in the layers appeared to be stable during the in situ radiation experiment and, as such, were used as fiducial marks. The density of newly generated defect clusters (labeled as 5 and 6 by red arrows) during radiation is low compared to that of pre-existing defects. Supplementary video 1 is provided to demonstrate the dynamics of $\mathrm{Cu} / \mathrm{Fe} 5$ multilayers exposed to $3 \mathrm{MeV} \mathrm{Cu}$ irradiation.

Statistical studies on evolution of the density and dimensions of defect clusters were performed on the irradiated monolithic $\mathrm{Cu}$ sample, the $\mathrm{Cu}$ layers of the $\mathrm{Cu} / \mathrm{Fe} 100 \mathrm{~nm}$, and $\mathrm{Cu} / \mathrm{Fe} 5 \mathrm{~nm}$ multilayer samples. As shown in Fig. 4a, defect density in irradiated monolithic $\mathrm{Cu}$ increased rapidly with dose and did not reach saturation by $0.5 \mathrm{dpa}(65)$. In contrast, defect density in the $\mathrm{Cu}$ layers of irradiated $\mathrm{Cu} / \mathrm{Fe} 100 \mathrm{~nm}$ multilayer samples increased much more slowly than that 
in monolithic $\mathrm{Cu}$, and by $0.5 \mathrm{dpa}$ appeared to saturate at a level approximately $1 / 5$ of that in monolithic $\mathrm{Cu}$. In the ion irradiated $\mathrm{Cu} / \mathrm{Fe} 5 \mathrm{~nm}$ multilayer sample, few defect clusters were generated during radiation, and the overall defect density barely changed as shown by a horizontal dash line in Fig. 4a. Meanwhile the pre-existing defects (growth defects) were stable during radiation.

Significantly lower defect density was observed in the $\mathrm{Cu} / \mathrm{Fe} 5 \mathrm{~nm}$ multilayer sample than that in the $\mathrm{Cu} / \mathrm{Fe} 100 \mathrm{~nm}$ multilayer. Another interesting observation is the average defect size, shown in Fig.4b, in monolithic $\mathrm{Cu}$ was $7 \pm 2 \mathrm{~nm}$, similar to that in the $\mathrm{Cu}$ layers in $\mathrm{Cu} / \mathrm{Fe}$ $100 \mathrm{~nm}$ multilayers: $9 \pm 3 \mathrm{~nm}$. In contrast, the defect size in irradiated $\mathrm{Cu} / \mathrm{Fe} 5 \mathrm{~nm}$ was $3 \pm 1 \mathrm{~nm}$ on average, with none exceeding the $5 \mathrm{~nm}$ layer thickness.

\section{Discussion}

The influence of $\mathrm{Cu} / \mathrm{Fe}$ layer interfaces on absorption of radiation induced defects

Incoherent layer interfaces in immiscible multilayer systems have been proven as defect sinks in irradiated multilayers $(24-26,41)$. The $\mathrm{Cu} / \mathrm{Fe}$ interfaces in irradiated $\mathrm{Cu} / \mathrm{Fe}$ multilayers also appear effective in alleviating radiation-induced damage. This in situ irradiation study shows a clear layer thickness dependence of defect density in irradiated $\mathrm{Cu} / \mathrm{Fe}$ multilayers: multilayers with smaller $\mathrm{h}$ show much lower radiation induced defect density than those in irradiated monolithic $\mathrm{Cu}$. Meanwhile, the smaller layer thickness $(\mathrm{h}=5 \mathrm{~nm})$ effectively restrain the growth of defect clusters in $\mathrm{Cu}$ layers, evidenced by the fact that the average defect size in the irradiated $\mathrm{Cu} / \mathrm{Fe} 5 \mathrm{~nm}$ multilayer (approximately $3 \mathrm{~nm}$ ) was much smaller than that in monolithic $\mathrm{Cu}$ and the $\mathrm{Cu} / \mathrm{Fe} 100 \mathrm{~nm}$ multilayer (approximately 7 and $9 \mathrm{~nm}$, respectively). In the $\mathrm{Cu} / \mathrm{Fe} 100 \mathrm{~nm}$ multilayers, the average grain size of $\mathrm{Cu}$ is $\sim 50 \mathrm{~nm}$, less than the individual layer 
thickness of $100 \mathrm{~nm}$. Subsequently, the grain boundaries may also have acted as defect sinks during in situ radiation.

A size effect on alleviation of radiation induced defect cluster density has been observed in several immiscible metallic multilayer systems. For instance radiation damage in terms of the density of $\mathrm{He}$ bubbles in $\mathrm{He}$ ion irradiated $\mathrm{Cu} / \mathrm{V}, \mathrm{Cu} / \mathrm{Nb}, \mathrm{Ag} / \mathrm{Ni}$ and $\mathrm{Ag} / \mathrm{V}$ multilayers decreases monotonically with decreasing $\mathrm{h}(38,42,48,52)$. Recently we reported that the density of $\mathrm{He}$ bubbles in $\mathrm{He}$ ion irradiated $\mathrm{Cu} / \mathrm{Fe}$ multilayers first decreased with decreasing $\mathrm{h}$ to approximately $5 \mathrm{~nm}$, and then increased at smaller $\mathrm{h}$, however, void swelling decreases monotonically with decreasing h (56).

The size effects on layer interface-alleviated radiation damage in numerous immiscible metallic multilayers seem to suggest that there should be a layer interface affected denuded zone, wherein the density of defect clusters decreases with proximity to the layer interface in comparison to the layer interior. It is challenging to directly observe interface affected (or defect denuded) zone by ex situ radiation experiments (58). There is indeed some in situ evidence that captured the absorption of mobile defect clusters by layer interface in immiscible $\mathrm{Ag} / \mathrm{Ni}$ multilayers (53). However the post radiation analysis or comparisons of individual images captured at different doses during radiation did not provide the in situ experimental existence of a layer interface affected zone. To address this question, we performed accumulative dose dependent studies in $\mathrm{Cu} / \mathrm{Fe}$ multilayers.

A statistical study of cumulative defect density in Cu layers in $\mathrm{Cu} / \mathrm{Fe} 100 \mathrm{~nm}$ multilayers irradiated over a dose of $0.25-0.31 \mathrm{dpa}$ in $160 \mathrm{~s}$ is provided in Fig. 5 (See the 4-times accelerated Supplementary Video 2 for details of the dynamics). A maximum defect density was 
identified in the middle of the $\mathrm{Cu}$ layer, whereas defect density quickly diminished on both sides of the centerline. The density of defect clusters in $\mathrm{Cu}$ reached a minimum level adjacent to the $\mathrm{Cu} / \mathrm{Fe}$ layer interfaces. Although there are still defects in the regions immediately adjacent to the layer interface, such a distribution of defect density clearly supports the prior hypothesis of the existence of a layer interface affected zone.

The existence of layer interface affected zones also implies that it is more difficult for defect clusters to nucleate near layer interfaces, as point defect density is lower approaching a layer interface, consistent with the reaction-diffusion model proposed by Demkowicz et al. (66). The defect density gradient leads to defect diffusion from grain interiors to layer interfaces. Therefore, the capability of multilayers to mitigate radiation damage by absorbing or eliminating radiation induced defects is enhanced when $\mathrm{h}$ is reduced to a dimension comparable to that of the fast diffusion zone suggested by the reaction-diffusion model (66).

We hypothesize that when $\mathrm{h}$ decreases to be comparable to the cascade size, long-range transport of interstitials away from the initial PKA due to focusing and channeling (67) is suppressed as a result of lattice and chemical discontinuity across layer interfaces. Therefore, the separation distances between radiation induced vacancies and interstitials are reduced at smaller $\mathrm{h}$, leading to enhanced vacancy-interstitial recombination. Meanwhile, defects generated near interfaces could also be absorbed by interfaces directly. Here we can estimate the average cascade size as follows. The average recoil energy under $1 \mathrm{MeV}$ heavy ion irradiation is $\sim 5 \mathrm{keV}$, although such an estimation has slight dependence on the mass of projectiles (67). The individual cascade diameter from a recoil of that energy is approximately $5 \mathrm{~nm}$ in $\mathrm{Cu}$ according to Averback's studies $(68,69)$. Therefore, in our experiments, the $3 \mathrm{MeV} \mathrm{Cu}$ ions may generate slightly larger cascades, comparable to $\mathrm{h}$ in the $\mathrm{Cu} / \mathrm{Fe} 5 \mathrm{~nm}$ multilayers. Such a crude estimation 
is consistent with fewer radiation induced defects and superior stability in irradiated $\mathrm{Cu} / \mathrm{Fe} 5 \mathrm{~nm}$ multilayers.

The formation of stacking fault tetrahedra in Cu in irradiated $\mathrm{Cu} / \mathrm{Fe} 100 \mathrm{~nm}$ multilayers

SFTs and dislocation loops are two major types of defect clusters in irradiated FCC metals. The defect types could be identified by various methods, including weak-beam dark field (WBDF) TEM (70), high-resolution TEM (HRTEM) (21) and high-resolution scanning TEM (71). In $\mathrm{Cu}$ with a low stacking fault energy (SFE), $55 \mathrm{~mJ} / \mathrm{m}^{2}(72)$, SFTs are frequently observed experimentally (73). Singh and Zinkle pointed out that half of the defect clusters in irradiated $\mathrm{Cu}$ are SFTs (64) and a previous study on proton irradiated $\mathrm{Cu}$ shows that $90 \%$ of defect clusters are SFTs (74). Our recent study shows that Kr ion irradiation also induced plenty of SFTs in $\mathrm{Cu}$ (75). Several theoretical studies have been performed to describe the formation mechanism of SFT as a result of irradiation $(76,77)$. Meanwhile, there are several pieces of in situ evidence on the formation of SFT, including the studies on Ni based superalloy (Inconel X750) (78), $\mathrm{Au}(79-81)$, and $\mathrm{Cu}$ (82). Here, we show bright-field TEM images of a SFT formation. As shown in Fig. 6, a small defect, a vacancy (Frank) loop emerged in the Cu layer next to the $\mathrm{Cu} / \mathrm{Fe}$ layer interface during in situ ion irradiation at $0 \mathrm{~s}$. The Frank loop continued to expand within the next $0.6 \mathrm{~s}$. By $1.5 \mathrm{~s}$, a defect stabilized into a triangular structure as a SFT (See Supplementary Video S3 for details). A SFT is a highly stable configuration of vacancy clusters in $\mathrm{Cu}$, and can be retained in FCC metals during radiation. Due to the dynamic nature of the in situ experiment, the nature of the Frank loop and SFT could not be confirmed using advanced TEM defect characterization techniques. 


\section{Conclusion}

We studied monolithic $\mathrm{Cu}$ films and $\mathrm{Cu} / \mathrm{Fe}$ multilayers with $\mathrm{h}$ of 100 and $5 \mathrm{~nm}$, subjected to in situ $\mathrm{Cu}$ ion irradiation at room temperature to approximately $1 \mathrm{dpa}$. A clear size effect in defect density and size was observed: in monolithic $\mathrm{Cu}$, rapid propagation of defect clusters was observed, whereas fewer defects (less than $1 / 5$ of defects in $\mathrm{Cu}$ ) were generated in $\mathrm{Cu} / \mathrm{Fe} 100 \mathrm{~nm}$ multilayers and radiation induced defects in $\mathrm{Cu} / \mathrm{Fe} 5 \mathrm{~nm}$ multilayers were difficult to identify. A statistical study in $100 \mathrm{~nm}$-thick $\mathrm{Cu}$ layers via in situ video reveals the existence of a layer interface affected zone in which the cumulative defect density declines near the $\mathrm{Cu} / \mathrm{Fe}$ interfaces. Meanwhile, the defect growth in $5 \mathrm{~nm}$-thick $\mathrm{Cu}$ layers was suppressed (approximately $3 \mathrm{~nm}$ ) by $\mathrm{Cu} / \mathrm{Fe}$ interfaces while the defect sizes in monolithic $\mathrm{Cu}$ (approximately $7 \mathrm{~nm}$ ) and $\mathrm{Cu}$ layers in $\mathrm{Cu} / \mathrm{Fe} 100 \mathrm{~nm}$ multilayer (approximately $9 \mathrm{~nm}$ ) are similar.

\section{Acknowledgements}

We acknowledge financial support by NSF DMR-1304101. Michael Marshall and Daniel Buller (Sandia National Laboratories) are acknowledged for their assistance with the TEM and ion beam. Work performed by KH and DCB was fully supported by the Division of Materials Science and Engineering, Office of Basic Energy Sciences, U.S. Department of Energy. Sandia National Laboratories is a multi-program laboratory managed and operated by Sandia Corporation, a wholly owned subsidiary of Lockheed Martin Corporation, for the U.S. Department of Energy's National Nuclear Security Administration under contract DE-AC0494AL85000. Access to microscopy and imaging center (MIC) at Texas A\&M University is also acknowledged. 


\section{References}

1. Mansur, L. K., Theory and experimental background on dimensional changes in irradiated alloys. J. Nucl. Mater. 216, 97 (1994).

2. Garner, F. A. et al., Comparison of swelling and irradiation creep behavior of fcc-austenitic and bcc-ferritic/martensitic alloys at high neutron exposure. J. Nucl. Mater. 276, 123 (2000).

3. Kiener, D. et al., In situ nanocompression testing of irradiated copper. Nature Mater. 10, 608 (2011).

4. Cawthorne, C. \& Fulton, E., Voids in irradiated stainless steel. Nature 216, 575 (1967).

5. Zinkle, S. J. \& Snead, L., Designing radiation resistance in materials for fusion energy. Annu. Rev. Mater. Res. 44, 241 (2014).

6. Ackland, G., Controlling Radiation Damage. Science 327, 1587 (2010).

7. Grimes, R. W. et al., Greater tolerance for nuclear materials. Nat. Mater. 7, 683 (2008).

8. Saito, S., Role of nuclear energy to a future society of shortage of energy resources and global warming. J. Nucl. Mater. 398, 1 (2010).

9. Was, G. S., Materials degradation in fission reactors: Lessons learned of relevance to fusion reactor systems. J. Nucl. Mater. 367-370, Part A, 11 (2007).

10. Bacon, D. J. et al., Computer simulation of threshold displacement events in alloys. J. Nucl. Mater. 205, 84 (1993).

11. Eldrup, M. et al., Dose dependence of defect accumulation in neutron irradiated copper and iron. J. Nucl. Mater. 307-311, Part 2, 912 (2002).

12. Victoria, M. et al., The microstructure and associated tensile properties of irradiated fcc and bcc metals. J. Nucl. Mater. 276, 114 (2000).

13. Caturla, M. J. et al., Comparative study of radiation damage accumulation in Cu and Fe. J. Nucl. Mater. 276, 13 (2000).

14. Bacon, D. J. et al., The primary damage state in fcc, bcc and hcp metals as seen in molecular dynamics simulations. J. Nucl. Mater. 276, 1 (2000).

15. Han, W. Z. et al., Effect of grain boundary character on sink efficiency. Acta Mater. 60, 6341 (2012).

16. Yu, K. Y. et al., Radiation damage in helium ion irradiated nanocrystalline Fe. J. Nucl. Mater. 425, 140 (2012).

17. Singh, B. N., Effect of grain size on void formation during high-energy electron irradiation of austenitic stainless steel. Philos. Mag. 29, 25 (1974).

18. Singh, B. N. \& Foreman, A. J. E., Calculated grain size-dependent vacancy supersaturation and its effect on void formation. Philos. Mag. 29, 847 (1974).

19. Beyerlein, I. J. et al., Defect-interface interactions. Prog. Mater Sci. 74, 125 (2015).

20. Yu, K. Y. et al., In situ studies of irradiation-induced twin boundary migration in nanotwinned Ag. Scripta Mater. 69, 385 (2013).

21. Yu, K. Y. et al., Removal of stacking-fault tetrahedra by twin boundaries in nanotwinned metals. Nat. Commun. 4, 1377 (2013).

22. Chen, Y. et al., Damage-tolerant nanotwinned metals with nanovoids under radiation environments. Nat. Commun. 6, 7036 (2015).

23. Li, J. et al., In situ study of defect migration dinetics and self-healing of twin boundaries in heavy ion irradiated nanotwinned metals. Nano Lett. 15, 2922 (2015). 
24. Zhang, X. et al., Interface-enabled defect reduction in He ion irradiated metallic multilayers. JOM 62, 75 (2010).

25. Demkowicz, M. J. et al., The role of interface structure in controlling high helium concentrations. Curr. Opin. Solid State Mater. Sci. 16, 101 (2012).

26. Misra, A. et al., The radiation damage tolerance of ultra-high strength nanolayered composites. JOM 59, 62 (2007).

27. Zhernenkov, M. et al., Trapping of implanted $\mathrm{He}$ at $\mathrm{Cu} / \mathrm{Nb}$ interfaces measured by neutron reflectometry. Appl. Phys. Lett. 98, 241913 (2011).

28. Kashinath, A. et al., Stable Storage of Helium in Nanoscale Platelets at Semicoherent Interfaces. Phys. Rev. Lett. 110, 086101 (2013).

29. Hattar, K. et al., Arrest of He bubble growth in Cu-Nb multilayer nanocomposites. Scripta Mater. 58, 541 (2008).

30. Anderoglu, O. et al., $\mathrm{He}^{+}$ion irradiation response of $\mathrm{Fe}-\mathrm{TiO}_{2}$ multilayers. J. Nucl. Mater. 435, 96 (2013).

31. Chen, Y. et al., In situ studies of radiation induced crystallization in Fe/a- $\mathrm{Y}_{2} \mathrm{O}_{3}$ nanolayers. J. Nucl. Mater. 452, 321 (2014).

32. Bai, X. M. et al., Efficient Annealing of Radiation Damage Near Grain Boundaries via Interstitial Emission. Science 327, 1631 (2010).

33. Chen, D. et al., Defect annihilation at grain boundaries in alpha-Fe. Sci. Rep. 3, 1450 (2013).

34. Song, M. et al., Response of equal channel angular extrusion processed ultrafine-grained T91 steel subjected to high temperature heavy ion irradiation. Acta Mater. 74, 285 (2014).

35. Wang, H. et al., Ion irradiation effects in nanocrystalline TiN coatings. Nucl. Instrum. Methods Phys. Res., Sect. B 261, 1162 (2007).

36. Shen, T. D. et al., Enhanced radiation tolerance in nanocrystalline $\mathrm{MgGa}_{2} \mathrm{O}_{4}$. Appl. Phys. Lett. 90, 263115 (2007).

37. Sun, C. et al., In situ Evidence of Defect Cluster Absorption by Grain Boundaries in $\mathrm{Kr}$ Ion Irradiated Nanocrystalline Ni. Metall. Mater. Trans. A 44, 1966 (2013).

38. Zhang, X. et al., Design of Radiation Tolerant Nanostructured Metallic Multilayers. J. Eng. Mater. Technol. 134, 041010 (2012).

39. Shao, S. et al., spiral patterns of dislocations at nodes in (111) semi-coherent fcc interfaces. Sci. Rep. 3, 2448 (2013).

40. Li, N. et al., Defect structures and hardening mechanisms in high dose helium ion implanted $\mathrm{Cu}$ and $\mathrm{Cu} / \mathrm{Nb}$ multilayer thin films. Int. J. Plast. 32, 1 (2012).

41. Mao, S. et al., Quantitative comparison of sink efficiency of $\mathrm{Cu}-\mathrm{Nb}, \mathrm{Cu}-\mathrm{V}$ and $\mathrm{Cu}-\mathrm{Ni}$ interfaces for point defects. Acta Mater. 82, 328 (2015).

42. Fu, E. G. et al., Size dependent enhancement of helium ion irradiation tolerance in sputtered $\mathrm{Cu} / \mathrm{V}$ nanolaminates. J. Nucl. Mater. 385, 629 (2009).

43. Fu, E. G. et al., Interface enabled defects reduction in helium ion irradiated Cu/V nanolayers. J. Nucl. Mater. 407, 178 (2010).

44. Fu, E. G. et al., Fluence-dependent radiation damage in helium (He) ion-irradiated $\mathrm{Cu} / \mathrm{V}$ multilayers. Philos. Mag. 93, 883 (2013).

45. Li, N. et al., The influence of interfaces on the formation of bubbles in He-ion-irradiated Cu/Mo nanolayers. Philos. Mag. Lett. 91, 18 (2010).

46. Gao, Y. et al., Radiation tolerance of Cu/W multilayered nanocomposites. J. Nucl. Mater. 413, 11 (2011).

47. Li, N. et al., He ion irradiation damage to Al/Nb multilayers. J. Appl. Phys. 105, 123522 (2009).

48. Wei, Q. M. et al., Suppression of irradiation hardening in nanoscale V/Ag multilayers. Acta Mater. 59, 6331 (2011). 
49. Wei, Q. M. et al., Nucleation and growth of bubbles in He ion-implanted V/Ag multilayers. Philos. Mag. 91, 553 (2010).

50. Heinisch, H. L. et al., The effects of interfaces on radiation damage production in layered metal composites. J. Nucl. Mater. 329-333, 924 (2004).

51. Chen, Y. et al., Unusual size-dependent strengthening mechanisms in helium ion-irradiated immiscible coherent Cu/Co nanolayers. Acta Mater. 84, 393 (2015).

52. $\mathrm{Yu}, \mathrm{K}$. Y. et al., Comparisons of radiation damage in He ion and proton irradiated immiscible Ag/Ni nanolayers. J. Nucl. Mater. 440, 310 (2013).

53. Yu, K. Y. et al., Superior tolerance of Ag/Ni multilayers against $\mathrm{Kr}$ ion irradiation: an in situ study. Philos. Mag. 93, 3547 (2013).

54. Li, N. et al., He ion irradiation damage in Fe/W nanolayer films. J. Nucl. Mater. 389, 233 (2009).

55. Yu, K. Y. et al., In situ observation of defect annihilation in $\mathrm{Kr}$ ion-irradiated bulk Fe/amorphous$\mathrm{Fe}_{2} \mathrm{Zr}$ nanocomposite alloy. Mater. Res. Lett. 3, 35 (2014).

56. Chen, Y. et al., Enhanced radiation tolerance in immiscible $\mathrm{Cu} / \mathrm{Fe}$ multilayers with coherent and incoherent layer interfaces. J. Mater. Res. 30, 1300 (2015).

57. Demkowicz, M. J. et al., Interface structure and radiation damage resistance in $\mathrm{Cu}-\mathrm{Nb}$ multilayer nanocomposites. Phys. Rev. Lett. 100, 136102 (2008).

58. Han, W. et al., Design of radiation tolerant materials via interface engineering. Adv. Mater. 25, 6975 (2013).

59. Chen, Y. et al., Microstructure and strengthening mechanisms in $\mathrm{Cu} / \mathrm{Fe}$ multilayers. Acta Mater. 60, 6312 (2012).

60. Hattar, K. et al., Concurrent in situ ion irradiation transmission electron microscope. Nucl. Instrum. Methods Phys. Res., Sect. B 338, 56 (2014).

61. Ziegler, J. F. \& Biersack, J. P., SRIM-2008, Stopping power and range of ions in matter. Calculation using the Stopping and Range of lons in Matter (SRIM) Code. $<$ http://www.srim.org/>. (2008).

62. Stoller, R. E. et al., On the use of SRIM for computing radiation damage exposure. Nucl. Instrum. Methods Phys. Res., Sect. B 310, 75 (2013).

63. Egerton, R., Electron energy-loss spectroscopy in the electron microscope. Springer Science \& Business Media, 2011.

64. Singh, B. N. \& Zinkle, S. J., Defect accumulation in pure fcc metals in the transient regime: a review. J. Nucl. Mater. 206, 212 (1993).

65. Li, N. et al., In situ probing of the evolution of irradiation-induced defects in copper. J. Nucl. Mater. 439, 185 (2013).

66. Demkowicz, M. J. et al., Influence of interface sink strength on the reduction of radiationinduced defect concentrations and fluxes in materials with large interface area per unit volume. Phys. Rev. B 84, 104102 (2011).

67. Was, G. S., Fundamentals of radiation materials science: metals and alloys. Springer, 2007.

68. Averback, R. S., Atomic displacement processes in irradiated metals. J. Nucl. Mater. 216, 49 (1994).

69. Nastasi, M., Ion-solid interactions: Fundamentals and applications. Cambridge University Press, 1996.

70. Kirk, M. et al., Characterization of irradiation defect structures and densities by transmission electron microscopy. J. Mater. Res. 30, 1195 (2015).

71. Lu, C. et al., Direct Observation of Defect Range and Evolution in Ion-Irradiated Single Crystalline $\mathrm{Ni}$ and Ni Binary Alloys. Sci. Rep. 6, (2016).

72. Gallagher, P. C. J., The influence of alloying, temperature, and related effects on the stacking fault energy. Metall. Trans. 1, 2429 (1970). 
73. Schäublin, R. et al., Irradiation-induced stacking fault tetrahedra in fcc metals. Philos. Mag. 85, 769 (2005).

74. Dai, Y. \& Victoria, M., in MRS Proceedings. (Cambridge Univ Press, 1996), vol. 439, pp. 319.

75. Chen, Y. et al., In situ studies on radiation tolerance of nanotwinned Cu. Acta Mater., (Accepted) (2016).

76. Wirth, B. D. et al., Atomistic simulation of stacking fault tetrahedra formation in Cu. J. Nucl. Mater. 283-287, 773 (2000).

77. Aidhy, D. S. et al., Point defect evolution in $\mathrm{Ni}, \mathrm{NiFe}$ and $\mathrm{NiCr}$ alloys from atomistic simulations and irradiation experiments. Acta Mater. 99, 69 (2015).

78. Yao, Z. \& Zhang, H. K., in Microscopy: advances in scientific research and education, A. MéndezVilas, Ed. (Formatex Research Center, Extremadura 2014), pp. 842-849.

79. Matsukawa, Y. \& Zinkle, S. J., One-dimensional fast migration of vacancy clusters in metals. Science 318, 959 (2007).

80. Wang, J. W. et al., Atomic-scale dynamic process of deformation-induced stacking fault tetrahedra in gold nanocrystals. Nat. Commun. 4, (2013).

81. Ishino, S. et al., In-situ observation of cascade damage in gold under heavy ion irradiation at high temperature. J. Nucl. Mater. 141, 776 (1986).

82. Arakawa, K. et al., A study of the mechanism of the growth and shrinkage of stacking fault tetrahedra using the fluctuation of their size under electron irradiation. J. Electron Microsc. 51, S225 (2002).

\section{Figure captions}

Fig. 1. A comparative overview of radiation damage in a monolithic $\mathrm{Cu}$ film, $\mathrm{Cu} / \mathrm{Fe} 100 \mathrm{~nm}$, and $\mathrm{Cu} / \mathrm{Fe} 5 \mathrm{~nm}$ multilayers irradiated by $3 \mathrm{MeV} \mathrm{Cu}$ ions to $0.5-1$ displacements-per-atom (dpa) at room temperature. (a) In the irradiated monolithic $\mathrm{Cu}$ subjected to a dose of $0.5 \mathrm{dpa}$, high-density defect clusters were generated. (b) Irradiation to $1 \mathrm{dpa}$ led to a moderate increase in defect density in the $\mathrm{Cu} / \mathrm{Fe} 100 \mathrm{~nm}$ multilayers. Nanoscale columnar grains in Fe layers remained after irradiation. Defect clusters were sporadically distributed primarily in the $\mathrm{Cu}$ layers. (c) Few defect clusters were detected in the irradiated $\mathrm{Cu} / \mathrm{Fe} 5 \mathrm{~nm}$ nanolayers.

Fig. 2. In situ TEM observation of radiation-induced microstructural evolution in the $\mathrm{Cu} / \mathrm{Fe} 100$ $\mathrm{nm}$ multilayers irradiated up to $1 \mathrm{dpa}$. (a) The $\mathrm{Cu}$ in as-deposited multilayers had a low defect density. (b) At 0.1 dpa, defect clusters appeared in Cu layers, as shown by the arrows. (c) When the dose increased to $0.5 \mathrm{dpa}$, the density of defect clusters also increased. (d) No significant increase of defect density was observed up to 1 dpa. Few discernable defect clusters were 
observed in the Fe layers throughout the entire radiation experiment. Layer interfaces remained essentially unchanged after irradiation.

Fig. 3. In situ TEM snapshots of defect evolutions in $\mathrm{Cu} / \mathrm{Fe} 5 \mathrm{~nm}$-thick multilayer irradiated to 1 dpa. Few defects (marked as 5-7 with red arrows) were generated in irradiated nanolayers. Several pre-existing (growth) defect clusters (marked as 1-4 by blue arrows) were identified as references and these pre-existing defect clusters only changed slightly during radiation. (The dynamics of defect generation and evolution is captured in Supplementary Video 1)

Fig. 4. A statistical study of identifiable defect cluster density and size in $\mathrm{Cu}$ ion irradiated monolithic $\mathrm{Cu}, 100$ nm-thick $\mathrm{Cu}$ layers in $\mathrm{Cu} / \mathrm{Fe} 100 \mathrm{~nm}$, and $\mathrm{Cu} / \mathrm{Fe} 5 \mathrm{~nm}$ multilayers. (a) In irradiated $\mathrm{Cu}$, the defect cluster density increased rapidly with dose. In contrast, the defect density in $\mathrm{Cu}$ layers in $\mathrm{Cu} / \mathrm{Fe} 100 \mathrm{~nm}$ multilayer was approximately $1 / 5$ of that in irradiated $\mathrm{Cu}$. Much fewer defects were generated in irradiated $\mathrm{Cu} / \mathrm{Fe} 5 \mathrm{~nm}$ multilayer and the dash line indicates no obvious increase in defect density. The solid lines are visual guides that illustrate the trend of defect density evolution. (b) The average detectable defect size in irradiated monolithic $\mathrm{Cu}$ is $7 \pm 2 \mathrm{~nm}$, compared to $9 \pm 3 \mathrm{~nm}$ for $\mathrm{Cu} / \mathrm{Fe} 100 \mathrm{~nm}$ and $3 \pm 1 \mathrm{~nm}$ for irradiated $\mathrm{Cu} / \mathrm{Fe} 5 \mathrm{~nm}$ multilayers.

Fig. 5. A statistical study on the accumulative number of identifiable defect clusters (normalized in unit of frequency by the total number of defect clusters, 90) generated in $\mathrm{Cu}$ layers in $\mathrm{Cu} / \mathrm{Fe}$ $100 \mathrm{~nm}$ multilayer over a dose range of 0.25-0.31 dpa in $160 \mathrm{~s}$ (see Supplementary Video 2). Each data point was obtained by counting defects in the measured regions (stripes) with dimension of $\sim 10 \times 350 \mathrm{~nm}$ in each $\mathrm{Cu}$ layer. It is evident that fewer defects are identified near the $\mathrm{Cu} / \mathrm{Fe}$ interfaces during radiation; in contrast, an increase in defect-generation frequency is observed further away from the layer interfaces and the defect-generation frequency reaches a maximum in the middle of the $\mathrm{Cu}$ layers. The dash line is a visual guide that delineates the defect-generation profile.

Fig. 6. In situ video snapshots capturing the evolution of a radiation induced defect cluster in a $\mathrm{Cu}$ layer in the $\mathrm{Cu} / \mathrm{Fe} 100 \mathrm{~nm}$ multilayer irradiated to $\sim 0.5 \mathrm{dpa}$. (a) At $\mathrm{t}=0 \mathrm{~s}$, a small defect cluster (likely to be a Frank loop) appeared in the $\mathrm{Cu}$ layer adjacent to the $\mathrm{Cu} / \mathrm{Fe}$ layer interface. (b-c) Within $0.6 \mathrm{~s}$, this defect cluster continued to evolve during radiation. (d) By $1.5 \mathrm{~s}$, the 
defect cluster transformed to a triangular defect, which may be a stacking fault tetrahedron (SFT) (The dynamics of this evolution process is provided in Supplementary Video 3). 

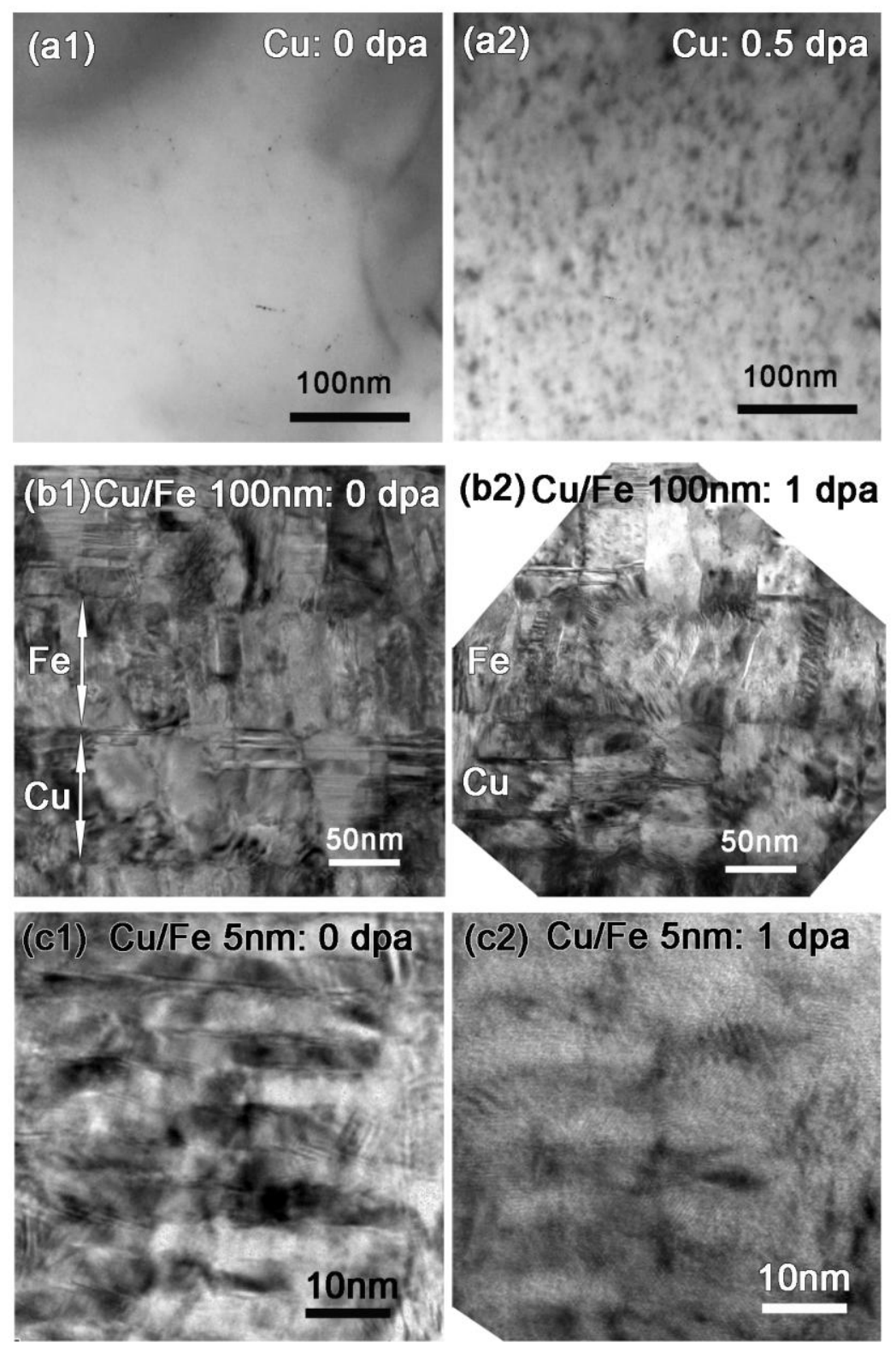

Figure 1 

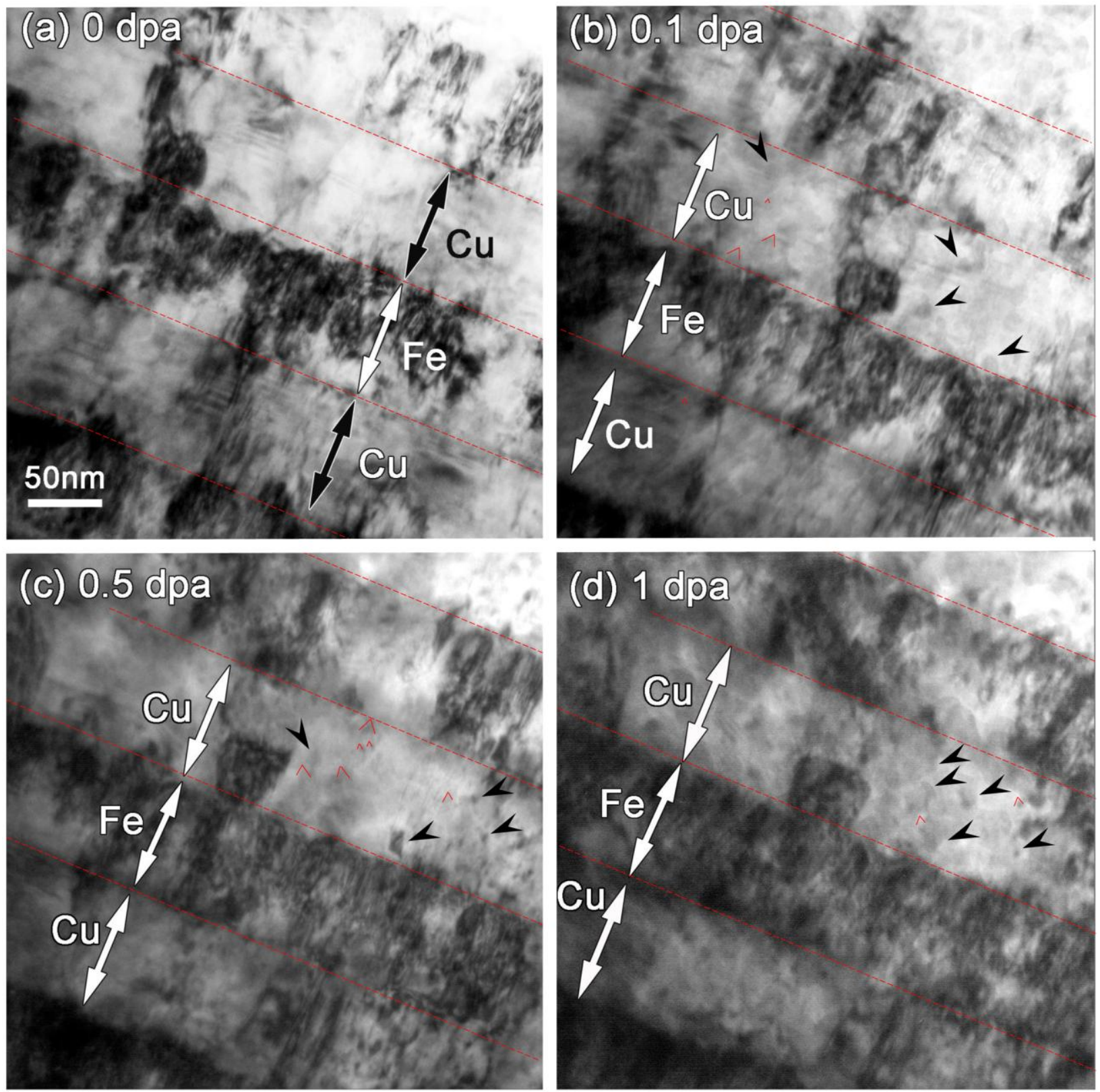

Figure 2 


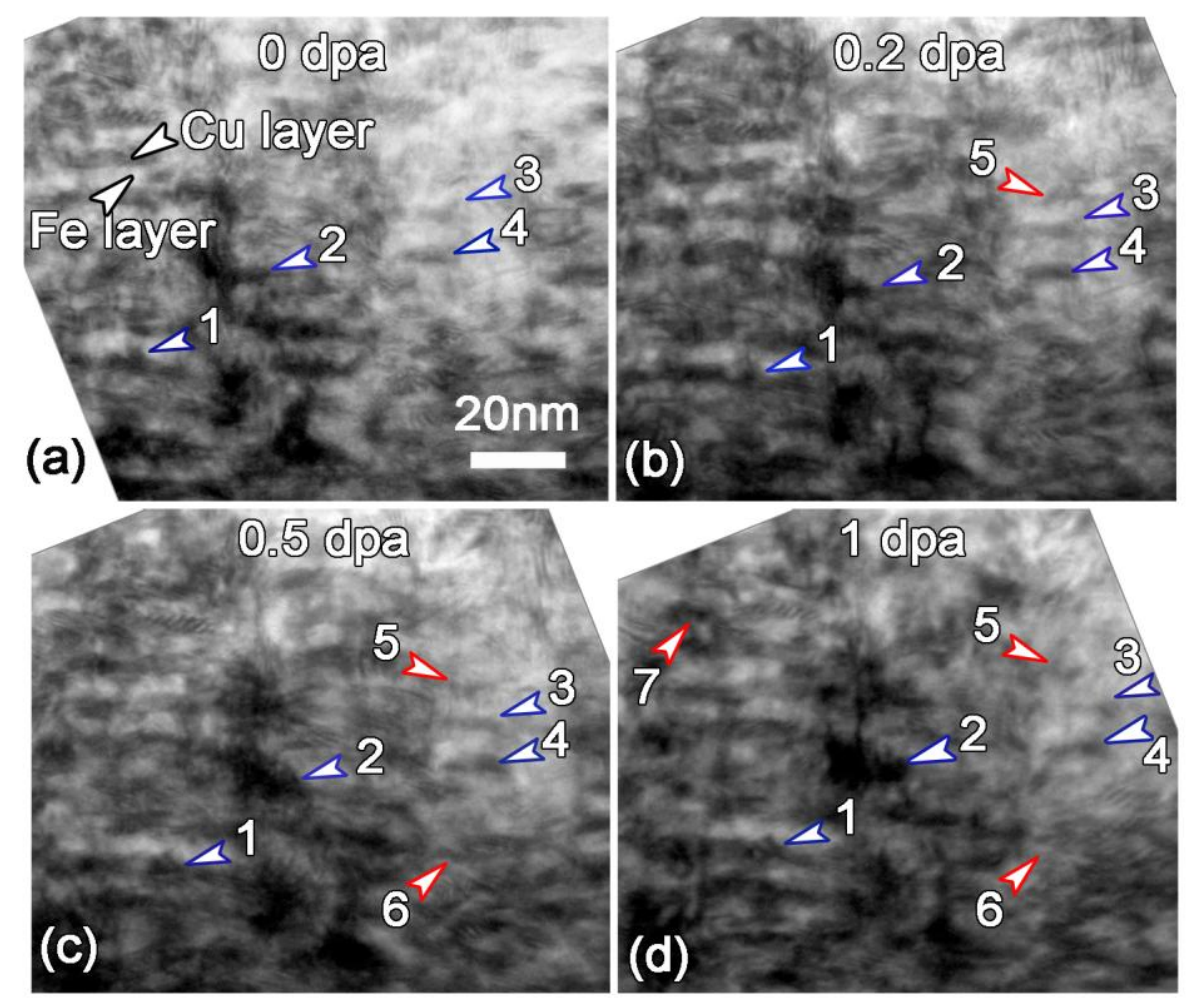

Figure 3 

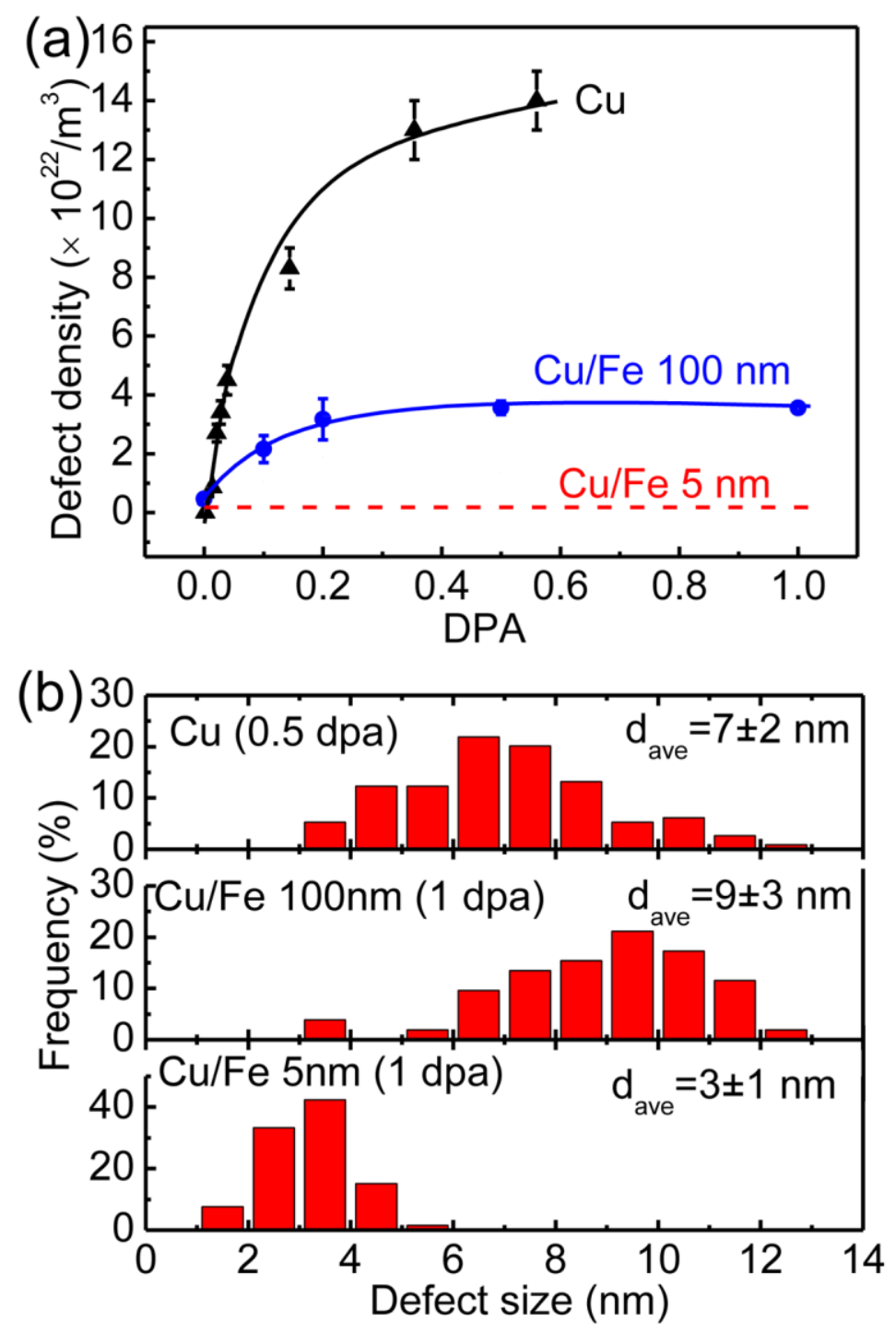

Figure 4 


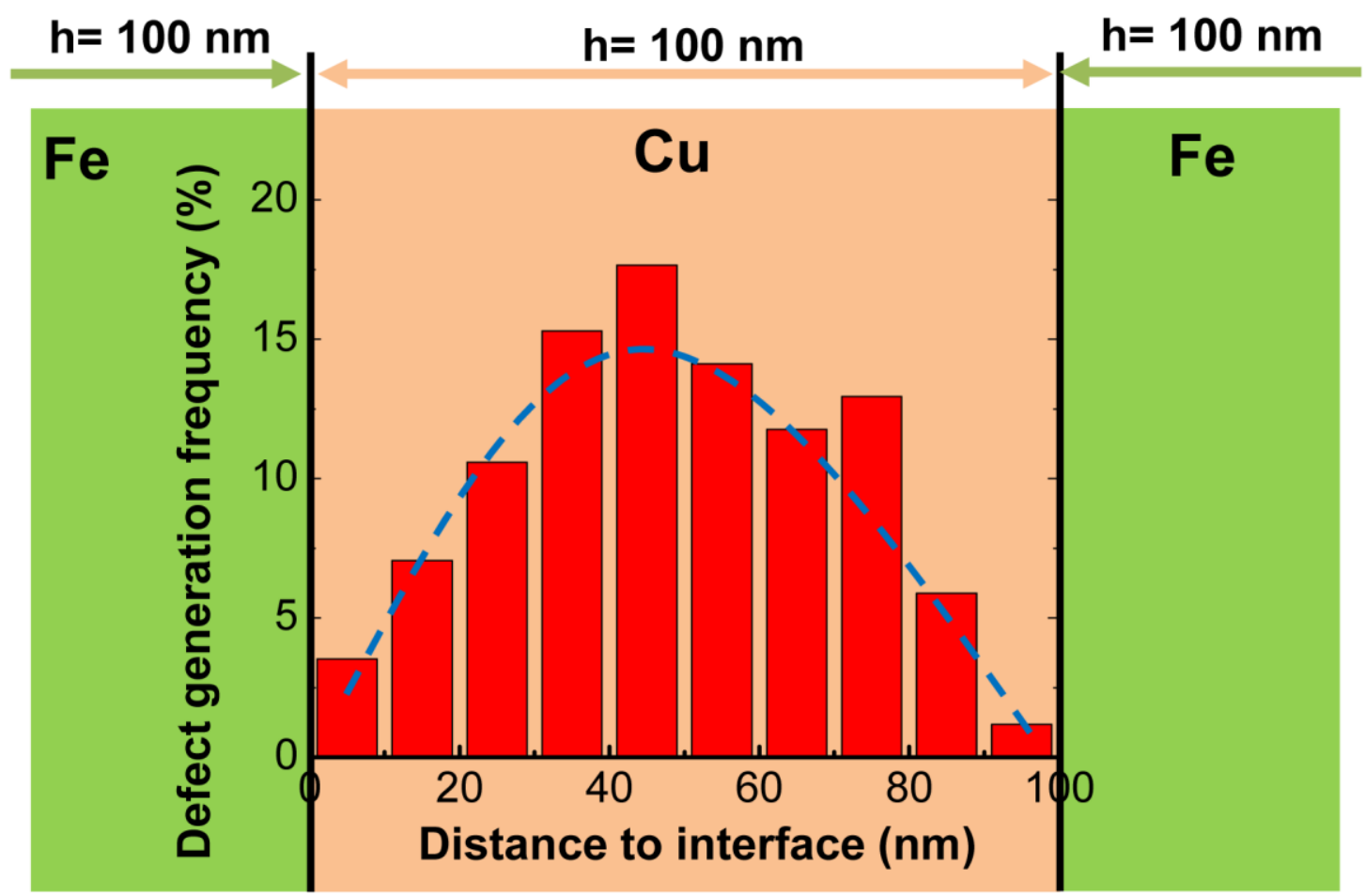

Figure 5 


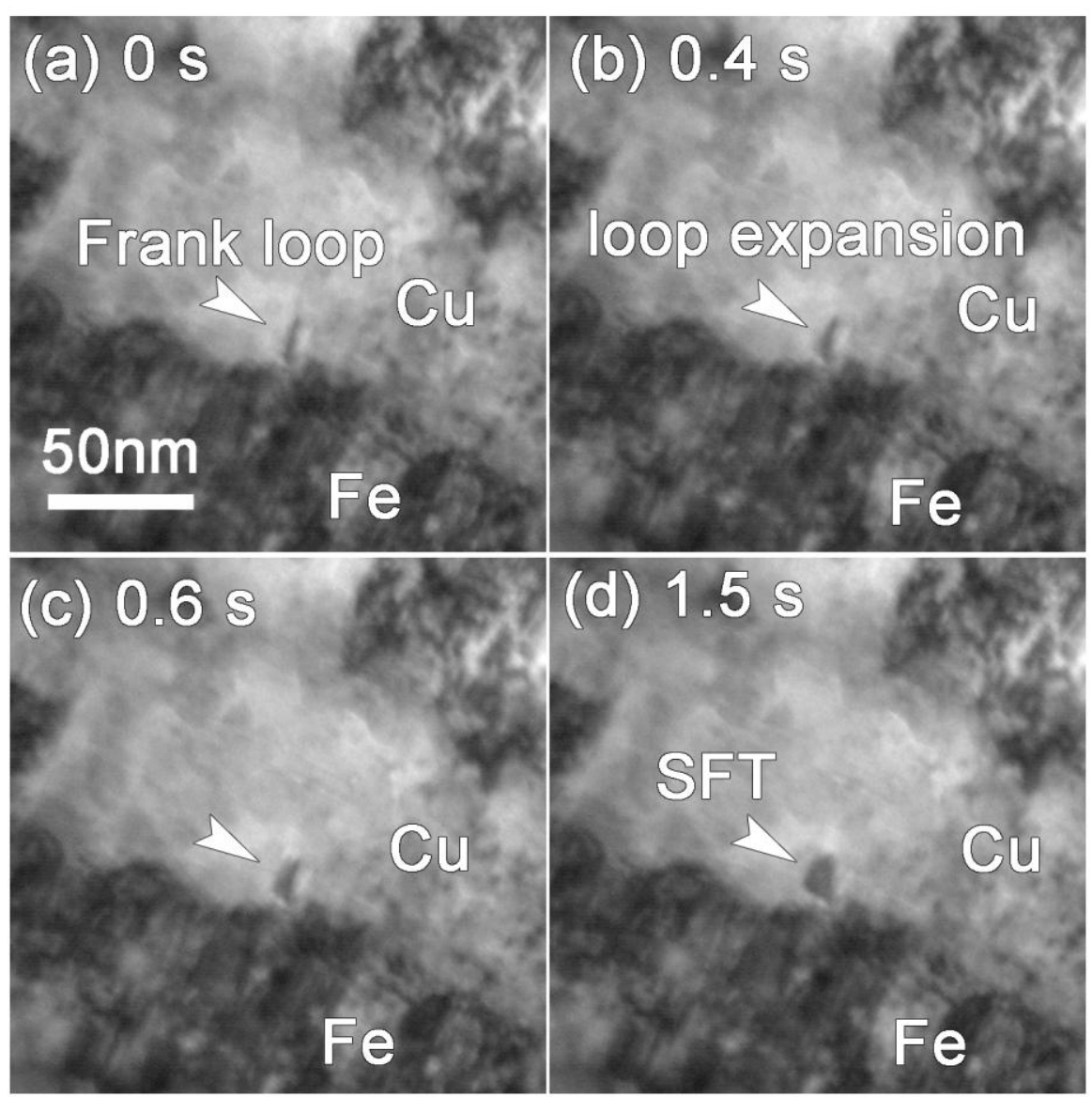

Figure 6 